\begin{tabular}{|cl}
\hline Jurnal Teknologi Kimia Unimal & $\begin{array}{l}\text { Jurnal } \\
\text { Teknologi } \\
\text { Kimia } \\
\text { Unimal }\end{array}$ \\
\hline
\end{tabular}

\title{
Aplikasi Kontrol PID Heat Exchanger Pabrik Etilen Glikol dengan Kapasitas 100.000 Ton/Tahun
}

\author{
Leni Maulinda, Chairun Nisa, Muhammad* \\ Jurusan Teknik Kimia, Fakultas Teknik, Universitas Malikussaleh \\ Kampus Utama Cot Teungku Nie Reuleut, Muara Batu, Aceh Utara - 24355 \\ KKorespondensi: mhdtk@unimal.ac.id
}

\begin{abstract}
Abstrak
Heat exchanger adalah suatu alat untuk penukar panas antara fasa yaitu suatu permukaan solid dan fluida atau antara partikel padat dan cairan pada suhu yang berbeda dan dalam kontak termal. Tujuan penelitian adalah untuk menentukan nilai optimum dari Kc, Ti, dan Td yang diaplikasikan pada peralatan kontrol Heat exchanger prarancangan pabrik etilen glikol. Penelitian ini juga menggunakan software design expert untuk membantu mendapatkan nilai optimum Kc, Ti, dan Td sebelum diaplikasikan pada sistem PID. Sistem kontrol Proportional-Integral-Derivative (PID) merupakan controller untuk menentukan presisi suatu sistem instrumentasi dengan karakteristik adanya umpan balik pada sistem tersebut (Feed back). Adapun metodologi penelitian ini adalah membuat model steady state Heat Exchanger, kemudian mengubah model steady state menjadi model dynamic, lalu membuat model kontrol PID, setelah itu melakukan tuning terhadap kontrol PID dan melakukan pengujian terhadap kontrol PID, dengan melakukan gangguan pada set point. Hasil dari pengaplikasian sistem kontrol PID maka didapatkan rata-rata waktu tercepat dengan nilai $\mathrm{Kc}=3, \mathrm{Ti}=$ 0,01 Td = 0,04 yaitu 0,77 menit. Pada suhu 147,6 $6^{\circ} \mathrm{C}$ didapatkan laju steam 290,8 Kg/Jam; pada suhu $148,6^{\circ} \mathrm{C}$ didapatka laju steam 297,7 Kg/Jam; Pada suhu $149,6^{\circ} \mathrm{C}$ didapatkan laju steam 305,0 Kg/Jam; Pada suhu $149,7^{\circ} \mathrm{C}$ didapatkan laju steam $305,8 \mathrm{Kg} / \mathrm{Jam}$ dan pada suhu $150^{\circ} \mathrm{C}$ didapatkan laju steam $308,1 \mathrm{Kg} / \mathrm{Jam}$.
\end{abstract}

Kata Kunci: $\quad$ heat exchanger, PID, set point

\begin{abstract}
Abstarct
Heat exchangers are tools used to transfer heat energy between a solid surface and fluid or inside different particles and in thermal contact. The objective of the study was to determine the optimum values of $\mathrm{Kc}, \mathrm{Ti}$ and $\mathrm{Td}$ which were applied to the control equipment of the ethylene glycol preparation exchanger. This research also uses design expert software to help get optimum vlue of $\mathrm{Kc}$, Ti and $\mathrm{Td}$ before applied to PID system. Proportional-Integral-Derivative (PID) is a controller to determine the precision of an instrumentation system with the characteristics of feedback on the system. As the methodology of this research is to create a steady
\end{abstract}


state Heat Exchanger model, then change the steady state model into a dynamic model, so create a PID model control, then tuning the PID control and testing PID controls, by disturbing the set point. The result of applying PID control system then got the fastest average time with value $\mathrm{Kc}=3, \mathrm{Ti}=0,01 \mathrm{Td}=0,04$ that is 0,77 minutes. At a temperature of 147.6 air vapor rate of $290.8 \mathrm{Kg} / \mathrm{hr}$; at a temperature of 148.6 found velocity speed of $297.7 \mathrm{Kg} / \mathrm{hr}$; At temperature 149.6 air vapor rate $305.0 \mathrm{Kg} /$ hour; At a temperature of 149.7 air vapor rate of 305.8 $\mathrm{Kg} /$ hour and at a temperature of 150 air vapor rate of $308.1 \mathrm{Kg} /$ Hour.

Keywords: $\quad$ heat exchanger, PID, set point

\section{Pendahuluan}

Pabrik Etilen glikol adalah salah satu pabrik industri kimia yang terus menerus mengalami peningkatan jumlah produksi setiap tahunnya baik di Indonesia maupun di seluruh dunia. Industri proses modern saat ini, misalnya industri Etilen glikol memiliki peralatan proses yang bekerja pada suhu dan tekanan ekstrem. Rangkain peralatan sudah sedemikian kompleks. Sementara kondisi proses bersifat dinamik. Dari waktu ke waktu dapat berubah-ubah. Perubahan sedikit pada kondisi proses bisa berakibat fatal. Inilah yang menjadi alasan diperlukan suatu sistem pengendalian. Masalah utama dalam perancangan kontrol PID adalah tuningnya (penentuan nilai Kc, Ti, Td). Adapun cara untuk mentuning ketiga parameter tersebut dapat menggunakan Metode Ziegler-Nicolas ataupun Metode Trial And Error. Pada penelitian ini, metode yang digunakan adalah metode kontrol PID secara trial and error. Tidak dapat dipungkiri, sampai saat ini kontrol PID (Proporsional Integral Derivative) merupakan satu satunya strategi yang paling banyak diadopsi pada pengontrolan variabel proses di industri. Kepopuleran PID sebagai komponen kontrol proses dilatar belakangi terutam oleh kederhanaan struktur, serta kemudahan dalam melalukan tuning parameter kontrolnya.

Penelitian ini bertujuan untuk mengevaluasi kondisi optimum pengoperasian alat penukar panas (HE-01) pada pabrik etilen glikol berdasarkan penyesuaian nilai parameter $\mathrm{Kc}$, $\mathrm{Ti}$ dan $\mathrm{Td}$ dalam upaya mendapatkan waktu respon minimum. 


\section{Tinjauan Pustaka}

\section{Heat Exchanger Shell and Tube}

Alat penukar panas cangkang dan buluh (Shell and Tube) terdiri atas suatu bundel pipa yang dihubungkan secara paralel dan ditempatkan dalam sebuah pipa mantel (cangkang). Fluida yang satu mengalir di dalam bundel pipa, sedangkan fluida yang lain mengalir di luar pipa pada arah yang sama, berlawanan, atau bersilangan. Kedua ujung pipa tersebut dilas pada penunjang pipa yang menempel pada mantel (buffle). Untuk meningkatkan efisiensi pertukaran panas, biasanya pada alat penukar panas cangkang dan buluh dipasang sekat (buffle). Ini bertujuan untuk membuat turbulensi aliran fluida dan menambah waktu tinggal (residence time), namun pemasangan sekat akan memperbesar pressure drop operasi dan menambah beban kerja pompa, sehingga laju alir fluida yang dipertukarkan panasnya harus diatur.

\section{Kendali PID}

Masalah mendasar sistem kontrol adalah tuning atau penalaan, yaitu menemukan nilai parameter yang tepat agar PV (Process Variable) dapat cepat mengejar harga SP (Set Point). Penambahan kontroler PID akan memperbaiki performansi sistem pengendalian. Pada aksi kontrol $\mathrm{P}$, mempunyai arti bahwa besarnya aksi kontrol sesuai dengan besarnya error dengan faktor pengali tertentu. Kelemahan dari aksi ini adalah terdapat steady state error yaitu output mempunyai selisih terdapat set point. Aksi kontrol integral (I) akan menghilangkan steady state error, artinya output sistem akan selalu mengejar set point sedekat mungkin. Aksi kontrol integral sering disebut automatic reset control. Kelemahan aksi kontrol integral adalah terjadinya osilasi sehingga mengurangi kestabilan sistem. Aksi kontrol (D) derivatif sering disebut rate control karena kecepatan perubahan error sebanding dengan sinyal kontrol. Artinya apabila ada perubahan error, maka sinyal kontrol beraksi. Aksi kontrol ini memberikan respon terhadap perubahan sinyal error dan mampu mengoreksinya sebelum error bertambah besar. Aksi kontrol ini mampu mengantisipasi error, mempercepat respon sistem dan meningkatkan stabilitas sistem. Kelemahan dari 
aksi ini adalah terdapat steady steate error karena error konstan tidak akan menghasilkan sinyal kontrol (sistem yang sudah steady tidak menghasilkan aksi kontrol walaupun jauh dari set point).

Aksi kontrol PID merupakan gabungan aksi kontrol dengan penambahan Proporsional, Integral dan derivatif secara bersamaan, yang akan menghasilkan performansi serta keuntungan gabungan ketiganya. PID mempunyai karakteristik reset kontrol dan rate kontrol yaitu meningkatkan respon dan stabilitas sistem serta mengeliminasi steady state error.

Persamaan kontrol PID dalam bentuk Laplace:

$\mathrm{U}(\mathrm{s})=\mathrm{K}_{\mathrm{p}}\left(\mathrm{E}(\mathrm{s})+\frac{1}{\mathrm{TiS}} \mathrm{E}(\mathrm{s})+\mathrm{T}_{\mathrm{D}} \mathrm{sE}(\mathrm{s})\right)$

\section{Metodologi Penelitian}

Penelitian ini menggunakan Software Aspen Hysys V8.8. Tahapan-tahapan yang perlu dilakukan adalah:

1. Membuat model steady state heat exchanger, flow chart dapat steady state dapat dilihat pada Gambar 1.

2. Mengubah model steady state menjadi mode dynamic heat exchanger,flow chart dapat dilihat pada Gambar 2.

3. Membuat model kontrol PID dan melakukan tuning Kc, Ti dan Td pada unit heat exchanger. Flow chart dapat dilihat pada Gambar 1 dan 2.

\section{Hasil dan Pembahasan}

Pengujian dilakukan untuk melihat respon waktu dari model kontrol dengan memvariasikan nilai setpoint pada range temperatur $(147,6 ; 148,6 ; 149,6 ; 149,7$; dan $150^{\circ} \mathrm{C}$ ). Parameter $\mathrm{Kc}$, Ti dan Td yang digunakan untuk penalaan (tuning) terdapat pada Tabel 1 .

Pengujian kontrol PID dengan nilai $\mathrm{Kc}=3, \mathrm{Ti}=0,01, \mathrm{Td}=0($ Gambar 3a), dimana dengan suhu $147,6^{\circ} \mathrm{C}$ didapat waktu respon 1,010 menit dengan laju 
steam $290 \mathrm{~kg} / \mathrm{jam}$, pada suhu $148,6^{\circ} \mathrm{C}$ didapat waktu respon 1,219 menit dengan laju steam $297,7 \mathrm{~kg} / \mathrm{jam}$, pada suhu $149,6^{\circ} \mathrm{C}$ didapat waktu respon 0,719 menit dengan laju steam $305 \mathrm{~kg} / \mathrm{jam}$, pada suhu $149,7^{\circ} \mathrm{C}$ didapat waktu respon 0,562 menit dengan laju steam $308,8 \mathrm{~kg} / \mathrm{jam}$, dan pada suhu $150^{\circ} \mathrm{C}$ didapat waktu respon 0,344 menit dengan laju steam $308,1 \mathrm{~kg} / \mathrm{jam}$ dan didapatkan waktu rata-rata 0,770 menit sedangkan bukaan valve (OP) sebesar 93,85\%.

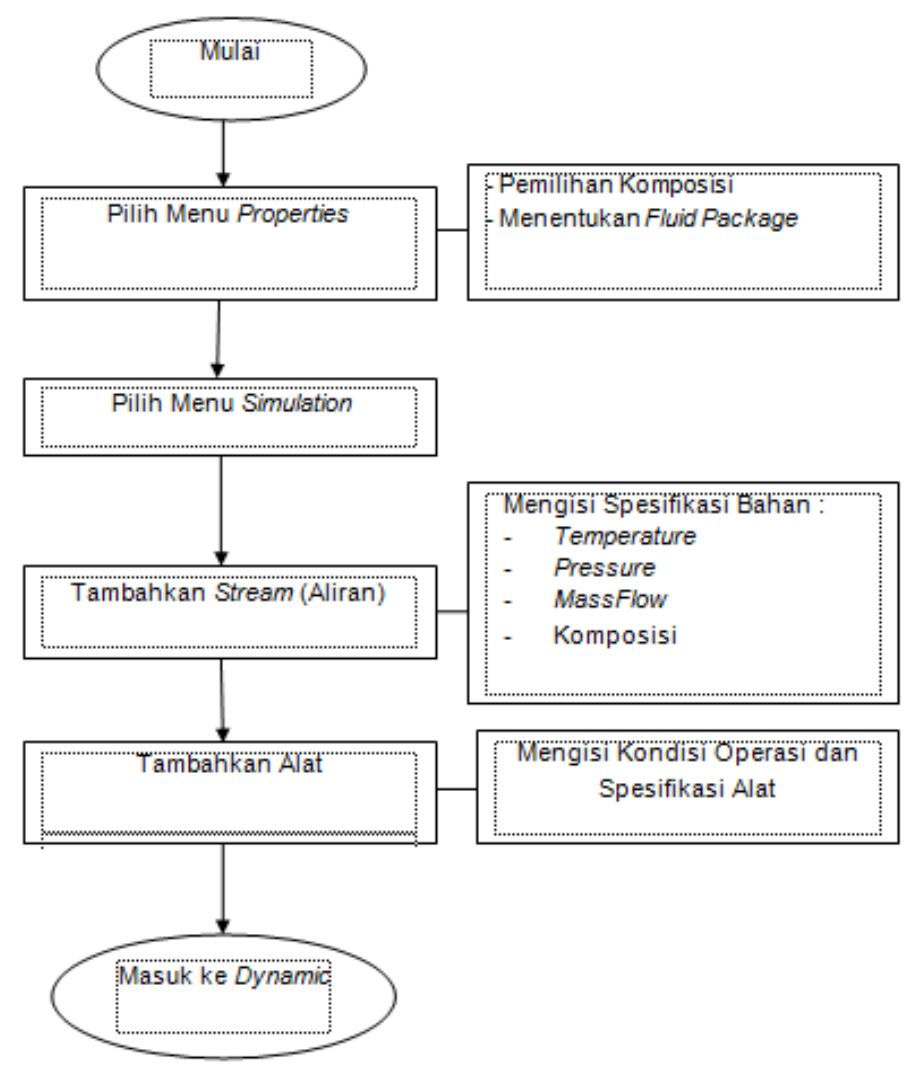

Gambar 1. Bagan Tahapan Penelitian (Steady State).

Gambar $3 b$ pengujian kontrol PID dengan nilai $\mathrm{Kc}=2, \mathrm{Ti}=0,01, \mathrm{Td}=0,09$ dimana dengan suhu $147,6^{\circ} \mathrm{C}$ didapat waktu respon 1,448 menit dengan laju steam $290,8 \mathrm{~kg} / \mathrm{jam}$, pada suhu $148,6^{\circ} \mathrm{C}$ didapat waktu respon 1,438 menit dengan laju steam $297,7 \mathrm{~kg} / \mathrm{jam}$, pada suhu $149,6^{\circ} \mathrm{C}$ didapat waktu respon 0,969 menit dengan laju steam $305,0 \mathrm{~kg} / \mathrm{jam}$, pada suhu $149,7^{\circ} \mathrm{C}$ didapat waktu respon 0,844 menit dengan laju steam $305,8 \mathrm{~kg} / \mathrm{jam}$, dan pada suhu $150^{\circ} \mathrm{C}$ didapat waktu respon 0,562 
menit dengan laju steam 308,1 kg/jam dan didapatkan waktu rata-rata 1,052 menit sedangkan bukaan valve (OP) sebesar 93,85\%.

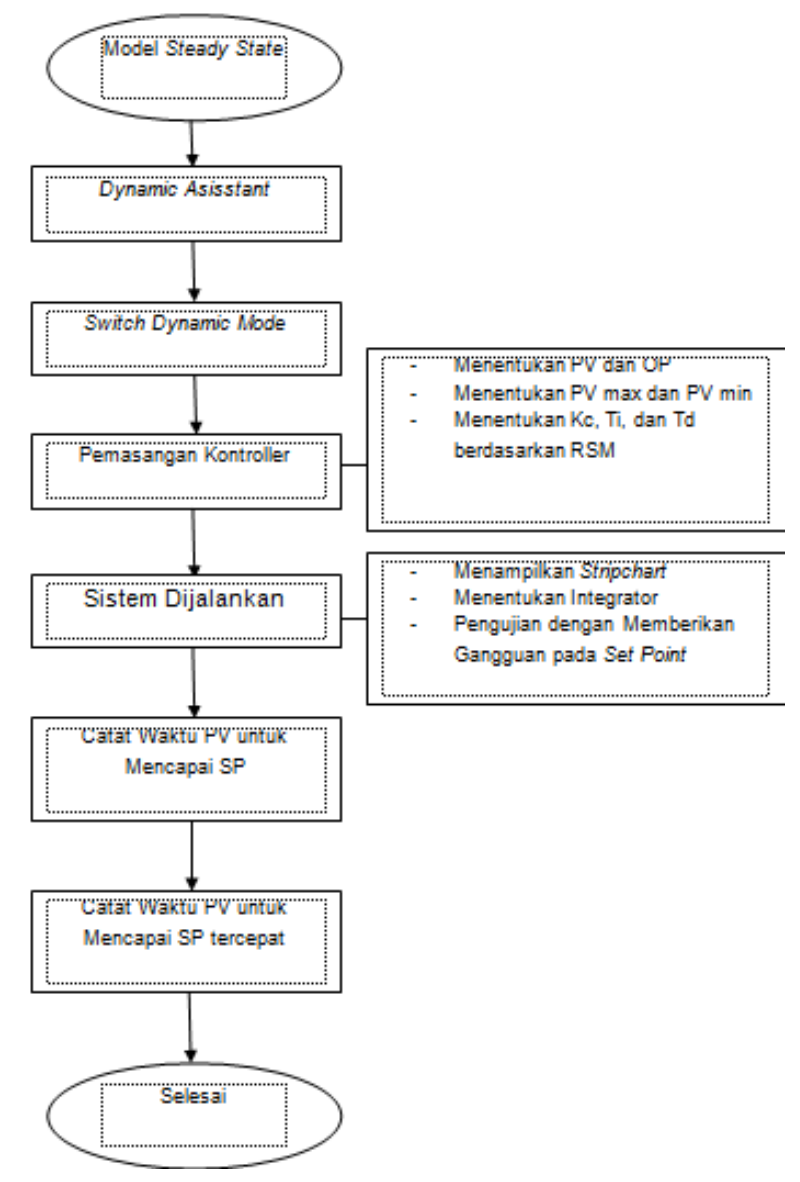

Gambar 2. Bagan Tahapan Penelitian (Dynamic).

Pengujian kontrol PID dengan nilai $\mathrm{Kc}=2, \mathrm{Ti}=0,01, \mathrm{Td}=0($ Gambar $3 \mathrm{c})$ dimana dengan suhu $147,6^{\circ} \mathrm{C}$ didapat waktu respon 1,542 menit dengan laju steam $290,8 \mathrm{~kg} / \mathrm{jam}$, pada suhu $148,6^{\circ} \mathrm{C}$ didapat waktu respon 1,281 menit dengan laju steam $297,7 \mathrm{~kg} / \mathrm{jam}$, pada suhu $149,6^{\circ} \mathrm{C}$ didapat waktu respon 1,031 menit dengan laju steam 305,0 kg/jam, pada suhu $149,7^{\circ} \mathrm{C}$ didapat waktu respon 1 menit dengan laju steam $305,8 \mathrm{~kg} / \mathrm{jam}$, dan pada suhu $150^{\circ} \mathrm{C}$ didapat waktu respon 0,531 menit dengan laju steam 308,1 kg/jam dan didapatkan waktu rata-rata 1,077 menit sedangkan bukaan valve (OP) sebesar 93,85\%.

Gambar 3d pengujian kontrol PID dengan nilai $\mathrm{Kc}=1, \mathrm{Ti}=0,03, \mathrm{Td}=0,04$ dimana dengan suhu $147,6^{\circ} \mathrm{C}$ didapat waktu respon 2,948 menit dengan laju steam 
Tabel 1 Parameter Kc, Ti dan Td digenerasikan menggunakan software Design Expert

\begin{tabular}{cccc}
\hline No & Kc & Ti & Td \\
\hline 1. & 3 & 0,01 & 0,04 \\
\hline 2. & 2 & 0,03 & 0,09 \\
\hline 3. & 3 & 0,02 & 0,09 \\
\hline 4. & 2 & 0,02 & 0,04 \\
\hline 5. & 1 & 0,02 & 0 \\
\hline 6. & 2 & 0,03 & 0 \\
\hline 7. & 2 & 0,01 & 0,09 \\
\hline 8. & 2 & 0,01 & 0 \\
\hline 9. & 3 & 0,02 & 0 \\
\hline 10. & 1 & 0,01 & 0,04 \\
\hline 11. & 3 & 0,03 & 0,04 \\
\hline 12. & 1 & 0,03 & 0,04 \\
\hline 13. & 1 & 0,02 & 0,09 \\
\hline
\end{tabular}

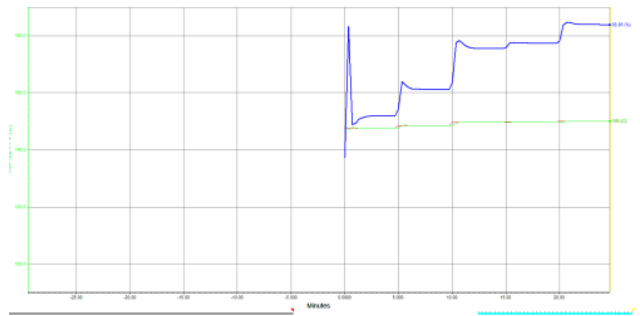

(a)

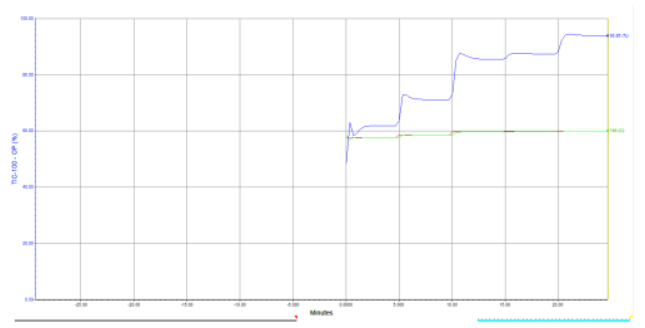

(c)

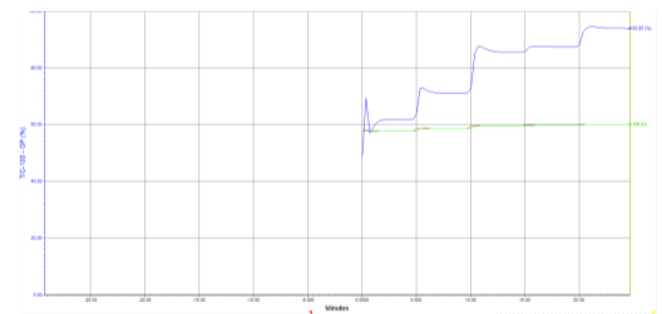

(b)

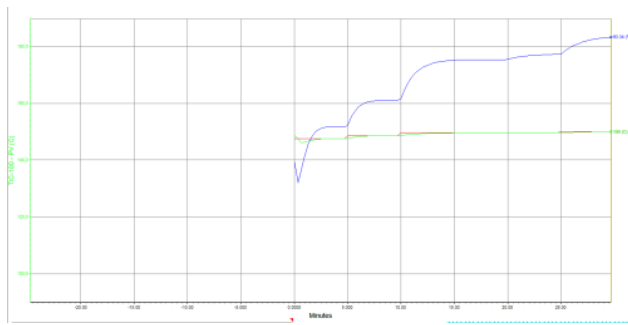

(d)

Gambar 3. Grafik hasil pengujian model PID (Keterangan Gan $\square \quad$ Garis proses variabel (PV), Garis setpoint (5,, Garis bukaan valve (OP).

$290,8 \mathrm{~kg} / \mathrm{jam}$, pada suhu $148,6^{\circ} \mathrm{C}$ didapat waktu respon 1,656 menit dengan laju steam $297,7 \mathrm{~kg} / \mathrm{jam}$, pada suhu $149,6^{\circ} \mathrm{C}$ didapat waktu respon 5,062 menit dengan laju steam $305,0 \mathrm{~kg} / \mathrm{jam}$, pada suhu $149,7^{\circ} \mathrm{C}$ didapat waktu respon 4,25 menit 
dengan laju steam $305,8 \mathrm{~kg} / \mathrm{jam}$, dan pada suhu $150^{\circ} \mathrm{C}$ didapat waktu respon 2,938 menit dengan laju steam $308,1 \mathrm{~kg} / \mathrm{jam}$ dan didapatkan waktu rata-rata 8,427 menit sedangkan bukaan valve (OP) sebesar 93,34\%.

Pengujian model PID membutuhkan penalaan (tuning) untuk mengatur agar control valve (final control element) merespon error. Dari hasil penalaan pada Gambar 3, terlihat grafik yang berbeda-beda. Hal tersebut dikarenakan nilai parameter Kc, Ti dan Td yang berbeda-beda pula. Dari Gambar 3 diketahui respon waktu tercepat didapatkan dari nilai parameter $\mathrm{Kc}=3, \mathrm{Ti}=0,01, \mathrm{Td}=0$. Dikarenakan besarnya nilai kontroler P yang selalu sesuai dengan besarnya error, oleh sebab itu dilakukan tuning dengan membuat nilai Kc lebih besar daripada nilai Td dan Td untuk mengurangi terjadinya offset. Jika dibandingkan dengan gambar lainnya, nilai Kc pada Gambar 3a lebih besar sehingga respon waktunya lebih cepat daripada gambar lainnya. Akan tetapi nilai Kc yang terlalu besar akan menyebabkan sistem cenderung tidak stabil (terjadi osilasi) sedangkan apabila nilai Kc terlalu kecil akan menyebabkan penyimpangan variabel proses (PV) yang terlalu besar seperti pada Gambar 3d. Selanjutnya perlu ditambahkan kendali integral yang berfungsi untuk menghilangkan offset. Sama halnya dengan Kc, nilai Ti yang terlalu besar akan menyebabkan sistem berosilasi seperti pada Gambar 3d dan apabila terlalu kecil akan mengakibatkan overshoot. Kemudian setelah dilakukan tuning pada Kc dan Ti respon waktu yang didapatkan sangat lambat. Oleh karena itu ditambahkan nilai Td sebanyak 0,04 agar mempercepat tanggapan sekaligus memperkecil overshoot variabel proses dengan memperbaiki respon transien.

Berdasarkan Gambar 3 hasil pengujian model PID terlihat adanya hubungan antara Set Point (SP), Process Variabel (PV) dan bukaan valve (OP). SP adalah nilai variabel proses yang diinginkan. PV adalah besaran yang menyatakan keadaan proses dan OP adalah controller output yang sebelumnya diubah dulu oleh transducer menjadi sinyal pneumatik untuk mengatur bukaan control valve sehingga didapatkan temperature yang diinginkan. Terlihat grafik SP cenderung tetap. Grafik PV bergerak naik dan turun menyamakan nilainya dengan SP. 
Perubahan naik turunnya PV berpengaruh terhadap persentase sinyal kontrol (OP). Terlihat nilai bukaan valve pada gambar 3a sebesar 93,85\% dan waktu respon rata-ratanya 0,771 menit. Sehingga dari hasil diketahui bahwa dengan nilai $\mathrm{Kc}=3, \mathrm{Ti}=0,01$ dan $\mathrm{Td}=0,01$ sebuah sistem pengendalian suhu dapat diterapkan untuk mendapatkan waktu yang paling optimal. Waktu yang optimal dapat memperkecil kemungkinan kecelakaan kerja, kerusakan peralatan, dan memperkecil keragaman kualitas dan produktivitas. Sehingga nantinya akan diperoleh kuantitas dan kualitas produk utama (yield) yang maksimum dengan biaya produksi minumum.

Penelitian ini diatur oleh valve agar proses berlangsung sesuai dengan yang diinginkan. Temperatur yang diinginkan atau SP yakni $148,6^{\circ} \mathrm{C}$, buka tutupnya valve dikendalikan oleh suatu Temperature Indicator Controller (TIC). Temperatur yang berasal dari proses sebelumnya dideteksi oleh suatu sensor. Data dari sensor dibaca oleh transmitter, kemudian diubah olehnya menjadi suatu sinyal yang dimengerti oleh controller. Data dari transmitter dikirimkan ke TIC kemudian datanya digunakan untuk dibandingkan dengan set point sehingga didapatkan pengontrolan bukaan valve dan temperatur yang diinginkan. Valve yang digunakan bertipe ATO (Air to Open). Fungsi control valve adalah mengatul laju steam. Prinsipnya adalah bertindak sebagai penyempitan variabel (variable restriction) dalam perpipaan proses. Sehingga semakin besar bukaan, maka laju steamnya juga semakin besar.

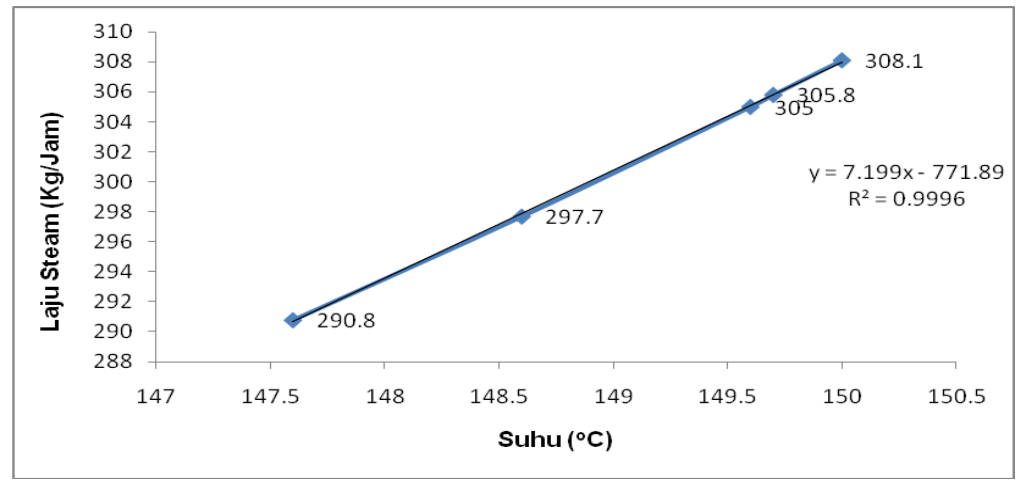

Gambar 4. Hubungan Suhu $\left({ }^{\circ} \mathrm{C}\right)$ Terhadap Laju Steam (Kg/Jam). 
Pengukuran suhu sangat berpengaruh terhadap laju steam yang masuk. Hubungan antara suhu $\left({ }^{\circ} \mathrm{C}\right)$ terhadap laju steam $(\mathrm{kg} / \mathrm{jam})$ yang masuk dapat dilihat pada Gambar 4.

Gambar 4 dapat diamati bahwa pada temperatur $147,6^{\circ} \mathrm{C}$ dengan laju steam $290,8 \mathrm{~kg} / \mathrm{jam}$, temperatur $148,6^{\circ} \mathrm{C}$ dengan laju steam $297,7 \mathrm{~kg} / \mathrm{jam}$, temperatur $149,6^{\circ} \mathrm{C}$ dengan laju steam $305 \mathrm{~kg} / \mathrm{jam}$, temperatur $149,7^{\circ} \mathrm{C}$ dengan laju steam $305,8 \mathrm{~kg} / \mathrm{jam}$, dan pada temperatur $150^{\circ} \mathrm{C}$ dengan laju steam $308,1 \mathrm{~kg} / \mathrm{jam}$. Dari hasil tersebut menunjukkan bahwa semakin tinggi temperatur maka akan menyebabkan laju steam semakin besar dan hal tersebut berbanding lurus dengan bukaan valve (OP) yaitu semakin besarnya bukaan valve yang dibuka akan menyebabkan laju steam meningkat. Peningkatan steam yang keluar menyebabkan proses berlangsung pada kondisi operasi yang tidak optimal artinya akan memperkecil keuntungan. Dari penelitian ini diketahui bahwa nilai Kc, Ti dan Td yang memiliki waktu respon tercepat dan laju steam yang optimal yaitu $\mathrm{Kc}=3 ; \mathrm{Ti}=0,01 ; \mathrm{Td}=0,04$ dengan waktu 0,770 menit dan laju steam 305,8 $\mathrm{Kg} / \mathrm{Jam}$. Laju steam yang optimal itu diketahui jika membandingkannya waktu respon dengan laju steam dari segi keuntungan ekonomi (profitability). Harga etilen glikol saat ini adalah 500 USD - 1000 USD/ton (alibaba,2017), dan jika dibandingkan dengan konsumsi steam yang digunakan sebanyak 305,8 kg/jam, maka masih proses masih dapat dikatakan optimal.

Pada penelitian ini nilai setpoint yaitu $148,6^{\circ} \mathrm{C}$. Untuk batas maksimum yang mampu dicapai setelah diberikan gangguan terhadap set pointnya yaitu $150^{\circ} \mathrm{C}$ dan untuk batas minimumnya yaitu $147,6^{\circ} \mathrm{C}$. Temperatur yang perlu dijaga pada penelitian ini yaitu temperatur keluaran tube heat exchanger yang akan diumpankan menuju reaktor.

Perbandingan hasil grafik pengujian PID dengan grafik perbandingan suhu terhadap laju steam yang didapat, bahwa variasi nilai $\mathrm{Kc}, \mathrm{Ti}, \mathrm{Td}$ hanya mempengaruhi cepat atau lamanya waktu yang dibutuhkan untuk mencapai set point dengan gangguan yang diberikan. 


\section{Simpulan}

Dari data hasil penelitian dapat diambil beberapa kesimpulan diantaranya, Kesesuaian nilai konstanta-konstanta $\mathrm{Kc}$, Ti, Td dapat mempengaruhi kemampuan dari kontroler untuk merespon gangguan dengan cepat. Waktu rata-rata tercepat dalam merespon gangguan dengan menvariasikan set point (temperatur) yaitu dengan nilai tuning parameter $\mathrm{Kc}=3 \mathrm{Ti}=0,01 \mathrm{Td}=0,04$ waktu yang dibutuhkan 0,77 menit. Untuk memenuhi konsumsi steam pada waktu 0,77 menit maka diperlukan bukaan valve steam $93,85 \%$.

\section{Daftar Pustaka}

Bansal, A., \& Sharma, V. (2013). Design and Analysis of Robust H-infinity Controller, 3(2), 7-14.

Budiyanto, 2014. Simulasi Kontrol PID untuk Mengatur Putaran Motor AC. Prosiding SNST Ke-5, 23-28.

Ferdinando, H. 2013. Desain PID Controller Dengan Software MatLab.

Hafid, M. 2014. Perancangan Kontroler Fuzzy PD untuk Kontrol, 3(1), 64-69.

Handoko. 2015. Model dan Simulasi Kendala Suhu, Kelembaban, dan Amonia pada Boiler Closed House berbasis ON-OFF, PID, Fuzzy Logic dan ANFIS. Model Dan Simulasi Kendala Suhu, Kelembaban, Dan Amonia Pada Boiler Closed House Berbasis ON-OFF, PID, Fuzzy Logic Dan ANFIS.

Kern, 1965. Process Heat Transfer. McGraw-Hill International Editions Chemical Engineering Series.

K.J. Astrom. 1997. Theory and Applications of Self-Tuning Regulators.

Mayne, J. B. R. and D. Q. 2010. Postface to "Model Predictive Control: Theory and Design.” Control, 57(5), 1040-50. https://doi.org/10.1109/TBME.2009.2039571.

Mushiri. 2017. A Model Reference Adaptive Control (MRAC) System for the Pneumatic Valve of the Bottle Washer in Beverages Using Simulink. Procedia Manufacturing, 7, 364-373. https://doi.org/10.1016/j.promfg.2016.12.003.

Neto, F. 2000. Adaptive PID Controllers Tuning: LMS Gain Scheduling Training and Industrial Progmmable Logic Controllers.

Purwanto. 2017. PID Controller Dengan Menggunakan Genetic Algorithm Pada 
Pengaturan Motor Induksi Sebagai Penggerak Mobil Listrik, (August).

Ralston, T. 2011. Getting Started - Preliminary Design - Aspen HYSYS Shell \& Tube Exchanger Design Utility, 9.

Setiawan, I. 2008. Kontrol PID untuk Proses Industri Beragam Struktur dan Metode Tuning Praktis.

Songsiri, J. 1994. Artificial neural networks in control and optimization. Doctor Thesis. University of Manchester. ..., (February). Retrieved from ftp://ftp.unicauca.edu.co/Documentos_Publicos/Facultades/FIET/DEIC/Mate rias/Control Inteligente/clases_2006a/Parte III/clase 23 int/RBF/chap01.pdf.

Syaichurrozi, I. 2014. Kajian Performa Alat Penukar Panas Plate and Frame: Pengaruh Laju Alir Massa, Temperatur Umpan dan Arah Aliran Terhadap Koefisien Perpindahan Panas Menyeluruh Study of Plate and Frame Heat Exchanger Performance: The Effects of Mass Flow Rate, Inlet Te, XI(2).

Wicaksono, H. 2004. Analisa Performansi dan Robustness Beberapa Metode Tuning Kontroler PID pada Motor DC, 4(2), 70-78. 